\title{
IDENTIFICATION OF SEASON-DEPENDENT RELATIONSHIPS BETWEEN SPECTRAL VEGETATION INDICES AND ABOVEGROUND PHYTOMASS IN ALPINE GRASSLAND BY USING FIELD SPECTROSCOPY
}

\author{
ANDREJ HALABUK, KATARÍNA GERHÁTOVÁ, FRANTIŠEK KOHÚT,ZZUZANA PO- \\ NECOVÁ, MATEJ MOJSES
}

Institute of Landscape Ecology, Slovak Academy of Sciences, Akademická 2, 94901 Nitra, Slovak Republic; e-mail: andrej.halabuk@savba.sk

\begin{abstract}
Halabuk A., Gerhátová K., Kohút F., Ponecová Z., Mojses M.: Identification of season-dependent relationships between spectral vegetation indices and aboveground phytomass in alpine grassland by using field spectroscopy. Ekológia (Bratislava), Vol. 32, No. 2, p. 186-196, 2013.

Spectral characteristics of alpine grasslands across the vegetation season (from May to September) are presented. The results are based on three year field spectroscopy monitoring of acid, nutrient poor grasslands at Králova hola research site, Low Tatras, Slovakia. Relationships between commonly used spectral vegetation indices (VIs) and field-based estimation of aboveground green phytomass (AGB) were analysed. Finally, season-dependent regression models were created in order to allow spatially extensive non-destructive monitoring of AGB. Spatial-temporal dynamics of background and standing litter markedly affect seasonal variations of relationships between VIs and AGB and predictability of the regression models. Because of a high proportion of litter during the whole season, this was a plant water-sensitive normalized difference water index (NDWI), which dominates as the predictive variable in the regression models across the whole season; except June, where chlorophyll absorption sensitive in normalized difference vegetation index (NDVI) performed the best $\left(\mathrm{R}^{2}=0.57\right.$; rel. RMSE $\left.=34 \%\right)$. However, the accuracy of the models was quite low (May: $R^{2}=0.45$; rel. RMSE $=49 \%$; July: $R^{2}=0.47$; rel. RMSE $=26 \%$; August: $R^{2}=0.13$; rel. RMSE $=31 \%$; September: $R^{2}=0.53$; rel. RMSE $\left.=40 \%\right)$.
\end{abstract}

Key words: alpine meadows, biomass, Tatra Mts, cropscan.

\section{Introduction}

Knowledge on spatial-temporal information of biomass distribution across different ecosystems has represented a major topic of ecosystem research for many years. Recently, permanent monitoring of aboveground biomass across the scales has been emphasized in order to obtain accurate estimates of carbon stocks (Running et al., 1999). Alpine grasslands represent natural and sensitive ecosystems, which make them a suitable candidate for climate change impact research (Kanka et al., 2005; Boltižiar, 2001; Hreško et al., 2012). However, in experimental and long-term configuration of the research, destructive techniques may 
substantially affect the vegetation which can lead to misinterpretation of the studied factor (e.g. warming) under consideration. In this paper we analysed a non-destructive method for monitoring green aboveground biomass (AGB) in the alpine grassland. A seasonal development of AGB can serve as a robust surrogate for net primary production (Scurlock et al., 2002) and represents key indicator of ecosystem response to environmental and climate change. However, a demanding nature of field work in the alpine grasslands makes spatial estimation of AGB by standard destructive techniques very difficult and ineffective. Field spectroscopy has been used for many years for estimation of AGB (Milton et al., 2009). In particular, various spectral vegetation indices (VIs) that are sensitive for specific biophysical and biochemical characteristics of vegetation (Ollinger, 2011) became very popular for rapid estimation of AGB. The hope for an up-scale of this approach by using satellite sensors has even more accelerated usage of the spectral vegetation indices. In this regard, field spectroscopy also plays a crucial role in the field validation of the satellite-based estimations of AGB (Milton et al., 2009).

Many examples exist that prove the suitability of VIs as measures of production in arctic tundra (Boelman et al., 2005), alpine grasslands (Shen et al., 2008) or mountain meadows (Vescovo, Gianelle, 2008). However, due to the great importance of arctic vegetation for global carbon balance, there are many more reports and studies from arctic vegetation than from alpine grasslands in the mountains. On the other hand, there are also many studies that document weak relationship between VIs and grassland AGB (e.g. Riedel et al., 2005; Chen et al., 2009; Psomas et al., 2011), which is besides complicated canopy structure often explained by negative effect of standing litter on linear response of VIs on green vegetation. Van Leeuwen, Huete (1996) reviewed many examples where VIs predicting power of regression models between VIs and AGB decreased due to background and standing litter. In fact, as a result of the short vegetation season and harsh climate, alpine grasslands represent a mixture of background (at the beginning of the season) and standing litter (progressively emerging from the mid season), which can substantially influence the suitability of VIs for AGB estimation. This might also be the reason why the seasonal effect on VIs vs. AGB relationship is well known and documented (Riedel et al., 2005; Fava et al., 2009).

In any case, based on the results from a study in arctic tundra, Hope et al. (1993) stated that the relationship between biophysical properties and spectral reflectance must be approached with caution because it may be unstable across a growing season due to vegetation phenology and background conditions. This proves the fact that empirical relations of VIs and AGB are markedly site specific and season dependent (Malenovský et al., 2009). Therefore, it is crucial to evaluate the performance of vegetation indices for many case studies in different vegetation types because this helps explain the diversity and discrepancy of studies and the continued need for further exploration in an attempt to establish common protocols and baseline information related to biophysical remote sensing within and between biomes (Leprieur, 2000; Laidler, Treitz, 2003).

The main motivation of our research is the development of non-destructive approach for monitoring of seasonal development of AGB in alpine grasslands. In this paper, we analyse the suitability of commonly used VIs for estimation of alpine grassland AGB. Particularly, we report basic spectral characteristics of the alpine grasslands across the vegetation season 
and season-specific relationships of AGB with VIs resulting in season-dependent regression models.

\section{Study area and methods}

The research was localized in the natural alpine grasslands at the Mt. Králová hol'a research site $\left(48^{\circ} 53^{\prime}, 20^{\circ} 07^{\prime}\right)$ at elevation of 1840 a.s.l. (Fig. 1). The grasslands at the research site belong to plant communities on acid substrates and shallow soils of the alliance Juncion trifidi Krajina 1933 represented by Oreochloa disticha, Festuca supina, Juncus trifidus, Carex nigra, Campanula alpina, Vaccinium vitis-idaea, Vaccinium myrtillus, Avenella flexuosa, Cetraria islandica, Cladonia sp. and Polytrichum sp. More detailed vegetation characteristics can be found in Barančok, Krajčí (2009). The mean annual temperature is $2^{\circ} \mathrm{C}$ and mean annual precipitation totals is $1200 \mathrm{~mm}$ (Faško, Štastný, 2002).

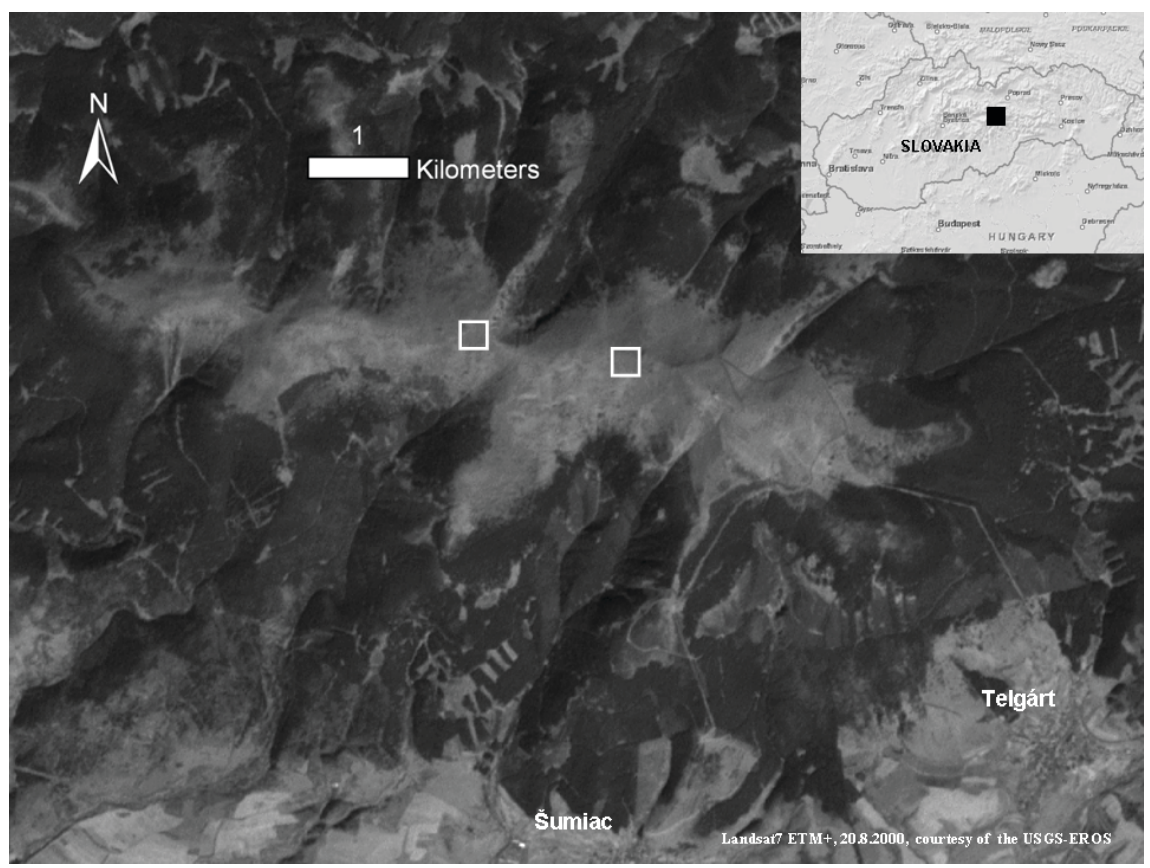

Fig. 1. Study site and sampling blocks.

A Cropscan 16 band multispectral field-portable radiometer (Cropscan, Inc., 2012) was used for field spectroscopy monitoring. Sixteen bands in radiometer were used in order to correspond to commonly used sensors such as Landsat TM5, MODIS and the planned Sentinel2 (Table 1). Cropscan contains upward- and downward-facing sensors in order to measure both incoming and reflected radiation, nearly simultaneously, which allows for useful reflectance readings in lightly cloudy conditions down to about $300 \mathrm{~W} \mathrm{~m}^{-2}$ incident irradiance (Cropscan, Inc., 2012). Sensors that measure reflected light have a $28^{\circ}$ field of view, which means that sampling plots $(30 \mathrm{x} 30$ $\mathrm{cm}$ ) were scanned at $70 \mathrm{~cm}$ height at nadir position in order to reflect the canopy under consideration.

Field spectroscopy measurements were done regularly, together with field-based biomass sampling during the three year research from May 2010 to September 2012. Only the measurements that meet the strict criteria, namely scanning in nearly cloud-free condition and near-solar noon, were used in later analyses in order to minimize bidirectional effects on reflectance measures due to variations of illumination angles. We need to notice that the specific high mountain climate (e.g. high air humidity and scattered low clouds) did not allow strict regularity 
Table 1. Filter bands used in 16 band multispectral radiometer CropScan.

\begin{tabular}{lll} 
Label & CWL $^{\mathbf{1}}(\mathbf{n m})$ & BW $^{2}(\mathbf{n m})$ \\
\hline b860 & 860 & 10 \\
b610 & 610 & 10.3 \\
b710 & 710 & 12.4 \\
b1240 & 1240 & 11.6 \\
b1540 & 1540 & 15.1 \\
b1650 & 1650 & 200 \\
b485 & 485 & 90 \\
b561 & 560 & 80 \\
b661 & 660 & 60 \\
b830 & 830 & 140 \\
b460 & 460 & 6.8 \\
b560 & 560 & 9.4 \\
b810 & 810 & 11.4 \\
b760 & 760 & 10 \\
b510 & 510 & 10 \\
b660 & 660 & 11.6 \\
& \\
& 1 centre wavelength & \\
${ }^{2}$ band width & & \\
\end{tabular}

of spectroscopy measurements, for example, every 14 days. Therefore, all the measurements from the whole three year period were aggregated to a monthly base.

Based on the spectral reflectance values, four commonly used VIs were calculated for their specific sensitivity to chlorophyll content: normalized difference vegetation index (NDVI; Rouse, 1974), green normalized difference vegetation index (GNDVI; Gitelson et al., 1996), red edge spectral parameter (RESP; Vogelmann et al., 1993); plant canopy structure: enhanced vegetation index (EVI; Huete et al., 2002); and water in plant tissue: normalized difference water index (NDWI; Gao, 1996). All the equations for the calculation of VIs are listed in the Table 2.

A standard destructive method for aboveground biomass estimation using $30^{\star} 30 \mathrm{~cm}$ quadrates was used. Vascular plants were carefully clipped just above the soil surface with razor blade. Two research blocks approx. 800 $\mathrm{m}$ from each other, with dimensions approx. $50^{\star} 50 \mathrm{~m}$ were used for the monitoring. Each research block was sampled by 12 randomly localized quadrates, that is 24 quadrates in total for the one date. Plant material was sorted out immediately in the laboratory in order to separate green phytomass and necromass. Finally, plant material was oven-dried at $75^{\circ} \mathrm{C}$ for $48 \mathrm{~h}$ and weighed.

T a b le 2. Spectral vegetation indices used in the study.

\begin{tabular}{lll} 
Vegetation index & Equation & References \\
\hline $\begin{array}{l}\text { Normalized difference vegetation index (NDVI) } \\
\text { Normalized difference water index (NDWI) }\end{array}$ & NDVI $=(\mathrm{b} 830-\mathrm{b} 661) /(\mathrm{b} 830+\mathrm{b} 661)$ & Rouse et al., 1974 \\
\hline Enhanced vegetation index & $2.5 \times \frac{(b 860-b 660)}{(b 860+6 \times b 660-7.5 \times b 460+1)}$ & Huete et al., 2002 \\
\hline Green normalized difference vegetation index (GNDVI) & GNDVI=(b860 - b560)/(b860+b560) & Gitelson et al.,1996 \\
\hline Red-edge spectral parameter (RESP) & RESP $=\mathrm{b} 760 / \mathrm{b} 710$ & Vogelmann et al., 1993
\end{tabular}

Pearson correlation coefficient $R$ was used for assessment of relationships between VIs and AGB. Linear regression using step wise selection of predicting variables was used for the whole period and respective months. Coefficient of determination $R^{2}$, root mean square error (RMSE) based on unstandardized residuals, and relative RMSE (proportion of RMSE to respective mean values of dependent variable) were used as a measure of accuracy of the models. All statistical analyses were done using Statistica v.9 software (StatSoft, Inc., 2009)

\section{Results}

Seasonal development of AGB in alpine grasslands reaches its maximum in July; spatial variability of AGB is the highest in May and decreasing simultaneously with growth of the green vegetation until August (Fig. 2). A substantial proportion of non-photosynthetically active vegetation (NPV) occurs during the whole season. It is highest in May, lowest in July and progressively increases until September following the development of standing litter. Thus, the proportion of the NPV reflects the two simultaneous processes - decomposition of background litter from the previous year and formation of the standing litter from the peak season. 


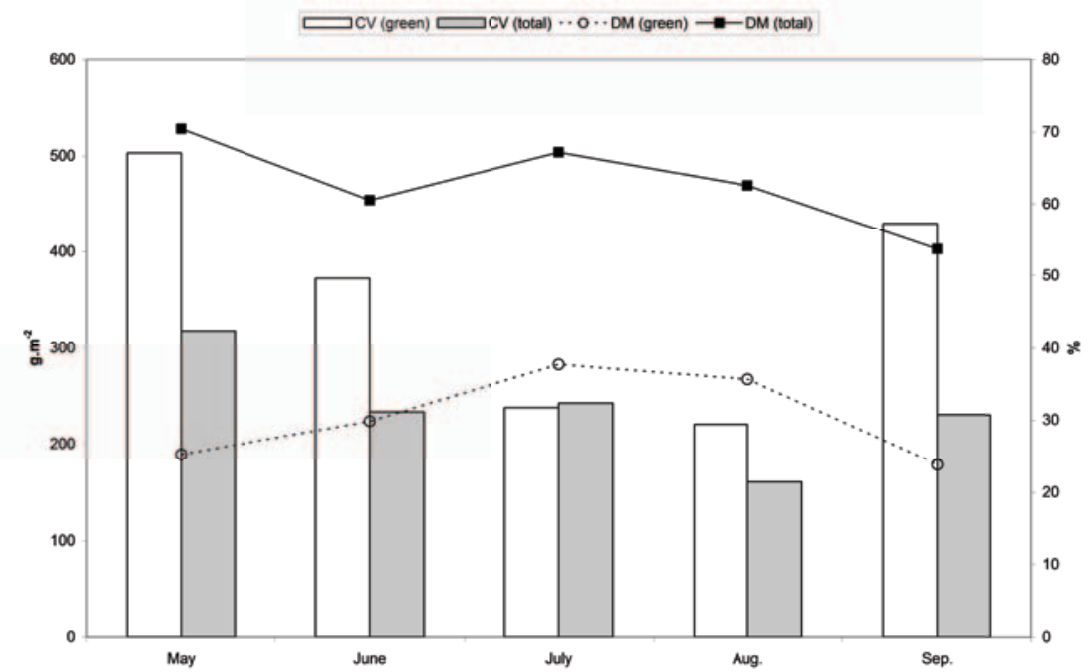

Fig. 2. Seasonal development of green phytomass and total aboveground phytomass (dry matter DM in $\mathrm{g} \mathrm{m}^{-2}$ ). Bars represent coefficients of variation (CV in \%).

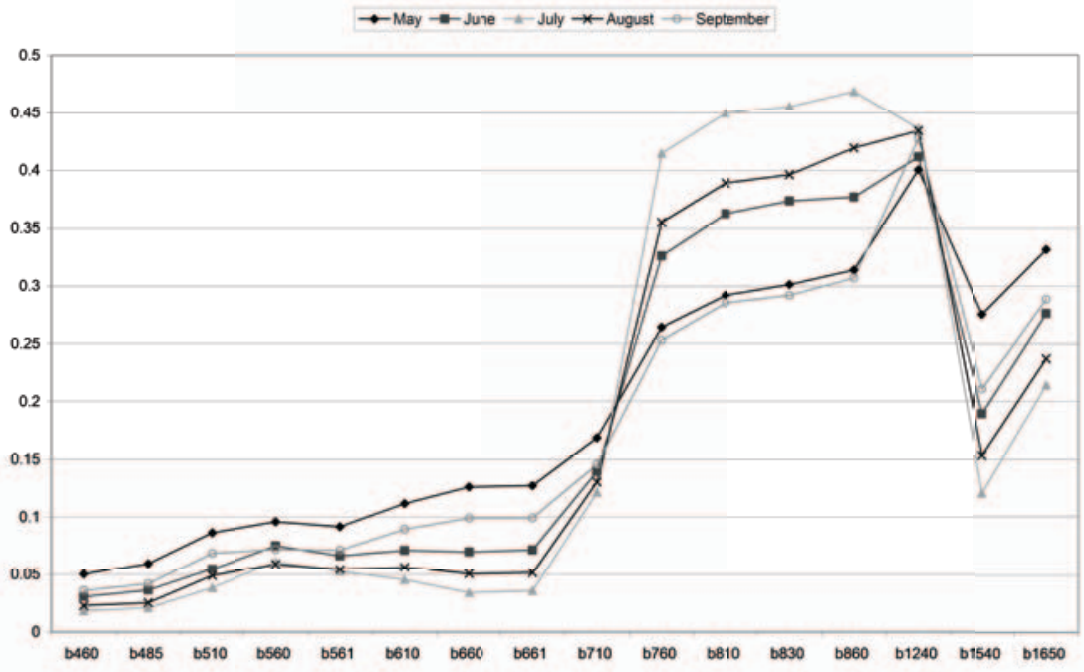

Fig. 3. Spectral characteristic (in reflectance units 0-1) in 16 spectral bands (see Table 1 for band width information) across the season.

The spectral characteristics of alpine grassland varied substantially across the season (Fig. 3 ). There is consistent difference in the chlorophyll absorption region (RED - $660 \mathrm{~nm}$ ), being the highest in July (the seasonal peak) and the lowest in May, which corresponds to the fraction of green phytomass in the stands (Fig. 2). In the near infrared region (NIR), where 
reflectance is driven mainly by scattering of incoming radiation, the far highest reflectance is visible in July followed by proportionally lower values in August and June (Fig. 3). The reflectance in the NIR region in May and September is about the same. The middle infrared region (MIR) is recognized as sensitive for plant water content since it has the low reflectance value where water absorption is high. This fact is identified in the 1540 and $1650 \mathrm{~nm}$ spectral region, having the lowest value in summer and the highest in early spring, which again follows the fraction of green vegetation development across the season (Fig. 2). Quite a divergent pattern was identified in the $1240 \mathrm{~nm}$ spectral region, which is discussed in the next section.

The development of seasonal temporal profiles of VIs generally corresponds to that of AGB. However, seasonal and spatial variability varies among the VIs as they are sensitive to slightly different canopy characteristics (Fig. 4). The highest amplitude is visible in the EVI and NDVI series. By far, the highest spatial variability is visible in NDWI. In addition, the well-known saturation of the NDVI and GNDVI is visible in July and August compared to EVI and RESP.

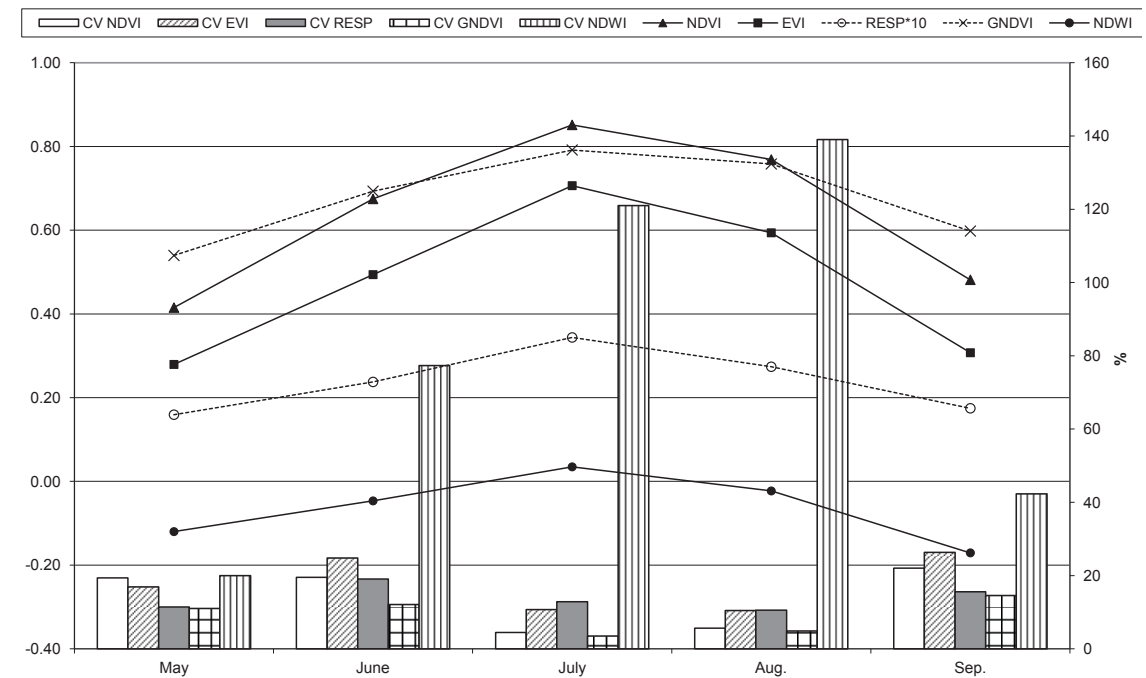

Fig. 4. Seasonal profile of spectral vegetation indices (unitless index from -1 to 1). Bars represent coefficients of variation (CV in \%).

When the whole season is considered, all the VIs correlate significantly with the AGB, with the highest rate in NDWI (Table 3). The seasonal variation of the relationships is quite diverse (Table 3). Only the NDWI correlates with AGB significantly in all months having the highest rate in May. Other VIs exert similar correlations with AGB, having the only significant correlations in June and no significant correlations in August and September. Except the NDWI, only NDVI shows significant correlation with AGB in July.

The coefficient of determination and RMSE of the season-dependent linear regression models are reported in Table 4. Except for the June model, where chlorophyll and structural sensitive VIs, namely NDVI, GNDVI and EVI, were selected, NDWI was selected as the 
$\mathrm{T}$ a b l e 3. Pearson correlation coefficients between spectral vegetation indices and green aboveground phytomass.

\begin{tabular}{lcccccc} 
Month & EVI & NDWI & GNDVI & NDVI & RESP & N \\
\hline May & 0.23 & $0.67^{\star *}$ & 0.17 & 0.28 & 0.22 & 32 \\
June & $0.48^{\star}$ & $0.51^{*}$ & $0.46^{*}$ & $0.55^{\star}$ & $0.46^{*}$ & 28 \\
July & 0.29 & $0.47^{\star *}$ & 0.08 & $0.34^{*}$ & 0.03 & 43 \\
August & 0.03 & $0.37^{*}$ & -0.25 & -0.16 & -0.08 & 36 \\
September & 0.23 & $0.58^{\star *}$ & -0.18 & 0.01 & 0.1 & 24 \\
\hline ALL & $0.45^{* *}$ & $0.53^{\star *}$ & $0.29^{* *}$ & $0.39^{* *}$ & $0.35^{\star *}$ & 199 \\
* correlation significant at 0.05 level & & & & \\
** correlation significant at 0.01 level & & & &
\end{tabular}

$\mathrm{T}$ a b l e 4. Selected variables, coefficients of determination and RMSE of the linear regression models.

\begin{tabular}{llllll} 
Model & Predictors & $\mathrm{R}$ & $\mathrm{R}^{2}$ & RMSE & rel. RMSE \\
\hline May & NDWI & 0.67 & 0.45 & 8.33 & 48.94 \\
June & NDVI. GNDVI. EVI & 0.76 & 0.57 & 6.94 & 34.46 \\
July & NDWI. RESP. NDVI & 0.69 & 0.47 & 6.55 & 25.75 \\
Aug. & NDWI & 0.36 & 0.13 & 7.33 & 30.46 \\
Sep. & NDWI. GNDVI. EVI & 0.73 & 0.53 & 6.41 & 39.83
\end{tabular}

T a b l e 5. Estimated coefficients of the season-dependent regression models.

\begin{tabular}{|c|c|c|c|c|c|c|}
\hline Model & & $\begin{array}{c}\text { Unstandardized } \\
\text { coefficients }\end{array}$ & $\begin{array}{l}\text { Standardized } \\
\text { coefficients }\end{array}$ & $t$ & Sig. & Partial Corr. \\
\hline \multirow[t]{2}{*}{ May } & (Constant) & 54.69 & & 6.93 & 0.00 & \\
\hline & NDWI & 315.06 & 0.67 & 4.87 & 0.00 & 0.67 \\
\hline \multirow[t]{4}{*}{ June } & (Constant) & 52.02 & & 2.38 & 0.03 & \\
\hline & NDVI & 376.08 & 4.57 & 4.38 & 0.00 & 0.67 \\
\hline & GNDVI & -292.44 & -2.26 & -3.57 & 0.00 & -0.59 \\
\hline & EVI & -166.26 & -1.88 & -3.07 & 0.01 & -0.53 \\
\hline \multirow[t]{4}{*}{ July } & (Constant) & -94.37 & & -2.17 & 0.04 & \\
\hline & NDWI & 84.20 & 0.39 & 2.25 & 0.03 & 0.34 \\
\hline & RESP & -201.49 & -0.98 & -4.24 & 0.00 & -0.56 \\
\hline & NDVI & 217.01 & 0.90 & 3.30 & 0.00 & 0.47 \\
\hline \multirow[t]{2}{*}{ Aug. } & (Constant) & 25.52 & & 15.89 & 0.00 & \\
\hline & NDWI & 89.32 & 0.36 & 2.15 & 0.04 & 0.36 \\
\hline \multirow[t]{4}{*}{ Sep. } & (Constant) & 50.29 & & 6.78 & 0.00 & \\
\hline & NDWI & 58.69 & 0.45 & 3.63 & 0.00 & 0.48 \\
\hline & GNDVI & -66.93 & -0.62 & -4.21 & 0.00 & -0.53 \\
\hline & EVI & 50.06 & 0.43 & 2.58 & 0.01 & 0.36 \\
\hline \multirow[t]{4}{*}{ ALL } & (Constant) & 34.94 & & 7.98 & 0.00 & \\
\hline & NDWI & 77.60 & 0.69 & 5.68 & 0.00 & 0.39 \\
\hline & RESP & -97.99 & -0.75 & -3.24 & 0.00 & -0.23 \\
\hline & EVI & 29.13 & 0.53 & 2.15 & 0.03 & 0.16 \\
\hline
\end{tabular}


predictive variable for all the models. The highest $R^{2}$ was obtained in the June model, and the lowest in August, the lowest relative error was again in the July model. All the coefficient estimates and partial correlation of the respective terms are listed in Table 5. The relative influence of selected predictive VIs is discussed in the later session.

\section{Discussion}

Spectral characteristics across the season varied substantially having the great NIR vs. RED contrast in July, which corresponds to the peak biomass season in alpine grassland. Seasonal variance of spectral characteristics in grasslands is obvious and was recognized by Fava et al. (2009) and Rundquist (2002) and may indicate specific phenology of the respective vegetation, management practices or litter dynamics. In our case this was mainly litter dynamics, which mainly drove seasonal variability of vegetation spectral response. Similar reflectance in the green region in June and September followed by contrast reflectance in the red region might be attributed to higher photosynthetic activity and chlorophyll content in June or proportionally higher negative effect of standing litter in canopy mixture in September than that of background litter in June. The NIR region can respond to canopy structural characteristics, such as LAI which might closely correlate to total biomass in the case of prevailing grassy species. In this respect, the similar spectral response in May and September might be caused by the fact that in May lower green photosynthetically active vegetation is present, but proportionally higher values of NPV phytomass (Fig. 2) can contribute to leaf reflectance in NIR. Another interesting divergence is visible in MIR $1240 \mathrm{~nm}$ spectral region compared to that of $1540 \mathrm{~nm}$ and $1650 \mathrm{~nm}$. Bearing in mind the great fraction of NPV in May and June compared to that in September, we suggest that MIR $1650 \mathrm{~nm}$ spectral region is more sensitive to NPV, whereas $1240 \mathrm{~nm}$ spectral region is sensitive to plant water.

In general, taking into account a whole season from May to September, NDWI performed at the highest rate in the regression models. When the whole season is considered, the predictive power of VIs substantially decreased, which stressed the fact that season-dependent relationships should be considered, mainly in the native grasslands where spatial-temporal variability of litter is high (Rundquist, 2002). Our results proved the substantial seasonal effect on the relationships between VIs and AGB. In our case this seasonal effect strongly corresponds to NPV seasonal dynamics.

A proportion of background litter in early spring (May) is substantially higher than green phytomass (Fig. 2), which might cause the fact that NDWI was selected as predictor for regression model in May. Vescovo, Gianelle (2008) and Psomas et al. (2011) report the higher predictive power of the regression models that include MIR wavelengths and stated that mainly sensitivity to water in plant tissue might be better for prediction of green phytomass in natural grasslands. Anyway the great amounts and spatial variability of background litter, which is undecomposed from previous season, might cause the relatively high r_rmse (48\%). Riedel et al. (2005) showed the $R^{2}$ for relationships between total live phytomass and NDVI in early spring is substantially lower than those of the early summer which might be caused by the similar effect of background litter in early spring and overgrown green phytomass in early summer. 
The strong fast development of green biomass in June is well reflected by chlorophyllsensitive indices such as NDVI, EVI and GNDVI. In early spring, background litter on the soil surface is obscured by green vegetation, thus green vegetation can be easily detected by the sensors of the radiometer. Many authors reported similar results stating that it is exactly at the beginning of the growing season when the strongest relationships between VIs and AGB can be found in natural grasslands (Psomas et al., 2011; Rundquist, 2002). However, the exact date of the highest relationships is vegetation and site specific, as the specific vegetation type may have different canopy structure and phenology of dominant species can vary substantially. This was proved by Boeleman et al. (2005) as they report substantially different values of $R^{2}$ for regression models between NDVI and AGB in wet sedge tundra $\left(R^{2}=0.84\right)$ and tussock tundra $\left(R^{2}=0.56\right)$. Similarly, values of $R^{2}$ for the regression model between NDVI and AGB in five major grassland types in Tibetan Plato ranges from 0.57 to 0.86 (Shen et al., 2008).

We think that the highest accuracy of the June model in our study is because of a maximum photosynthetic activity at the beginning of the season (June) and relatively simple double layer design of the grassland, meaning that green phytomass is the upper layer and is not mixed with any standing litter as it is in the late season. However, background litter on the soil surface with high spatial variability still affects the performance of VIs, which results in relatively high r_rmse.

Late July is regarded as the peak biomass season in alpine grasslands, thus estimation of AGB at peak season is thought to be crucial for total approximation of production. Therefore many authors report only the VIs-AGB relationships from this period. In our case, as the season proceeds, standing litter appeared progressively till the late season when it dominates the stands. In this respect, inclusion of NDWI in the models from July reflects the standing litter and sensitivity to plant water dominates the regression models until the late season. Similarly, Kushida et al. (2009) report from sedge-shrub tundra $R^{2}$ of linear estimation of the green phytomass and NDVI of 0.39 , whereas by using NDII (the same as NDWI, while using MIR at $1650 \mathrm{~nm}$ spectral region instead of $1240 \mathrm{~nm}$ ) they get $R^{2}$ of 0.63 . Although not substantially, RESP was included in the regression model for July, which might prove the suitability of RED-EDGE based indices in prediction of AGB when vegetation greenness is saturated (Mutanga, Skidmore, 2004) as was later proved by Chen et al. (2009) for alpine grasslands with high canopy cover, although they also report relatively weak relationship between VIs and AGB with $R^{2}$ ranges from 0.13 to 0.3 . As a result in the peak biomass season, NDWI, RESP and NDVI predict the best AGB, although the reason for negative partial correlation of RESP needs to be better explored in further ecophysiological research at the site.

The lowest relationship between AGB and VIs was found in August, which we think was mainly due to occurrence of standing litter, which make the canopy structure complicated having the variable NPV to PV ratio. Similarly, Riedel et al. (2005) reported substantially lower predictive power of August regression model ( $R^{2}$ approx. 0.12$)$ compared to that of July ( $R^{2}$ approx. 0.6). In our case, the September regression model performed better compared to that of August. We think that this is due to the simpler canopy structure representing by standing litter that dominates the upper level of the canopy, which again allows predictability of AGB by NDWI. 


\section{Conclusion}

To conclude, spectral characteristics of the alpine grasslands varied substantially in spatial and seasonal terms. The main reason for this is mainly a spatial-temporal variation of background litter in the beginning of the season and progressing development of standing litter from august to late season. The higher proportions of the litter across the whole season results in suitability of VIs, which include MIR band, that are sensitive to water in plant tissues. Even though predictability of the models was relatively low, bearing in mind the difficulties of the field work in the alpine environment, we think that these models may be used for non-destructive estimation of AGB in experimental research (June model) or in monitoring of AGB (July model) in alpine grasslands. However, more research using field spectroscopy in alpine grasslands is needed and this should include another vegetation types in order to approach the common protocols for monitoring of alpine grasslands with respect to their response to changing environment. Field spectroscopy using broadband indices should be considered in this effort because of upcoming satellite missions such as Sentinels2, which bring hope for up-scaling of the field-based evidence to broader scales.

\section{Acknowledgements}

This work was fully supported by the Scientific Grant Agency of the Ministry of Education of Slovak Republic and the Academy of Sciences under Grant No. 2/0217/09.

\section{References}

Barančok, P. \& Krajčí J. (2009). Vegetácia subalpínskeho a alpínskeho stupňa Královohol’ských Tatier. In P. Turis \& L. Vidlička (Eds.), Príroda Nízkych Tatier 2 (pp. 87-107). Banská Bystrica: Správa NP Nízke Tatry.

Boelman, N.T., Stieglitz, M., Griffin, K.L. \& Shaver G.R. (2005). Inter-annual variability of NDVI in response to long-term warming and fertilization in wet sedge and tussock tundra. Oecologia, 143(4), 588-597. DOI: 0.1007/s00442-005-0012-9.

Boltižiar, M. (2001). Evaluation of vulnerability of high-mountain landscape on example Velická valley in the High Tatras Mts. Ekológia (Bratislava), 20(Suppl. 4), 101-109.

Chen, J., Gu, S., Shen, M.G., Tang, Z.H. \& Matsushita B. (2009). Estimating aboveground biomass of grassland having a high canopy cover: an exploratory analysis of in situ hyperspectral data. Int. J. Remote Sens., 30(24), 6497-6517. DOI: 10.1080/01431160902882496.

Cropscan, Inc. (2012). http://www.cropscan.com/techsupt.html.

Faško, P. \& Štastný P. (2002), Mean annual precipitation totals (in Slovak). In Atlas krajiny SR. Bratislava: MŽP SR.

Fava, F., Colombo, R., Bocchi, S., Meroni, M., Sitzia, M., Fois, N. \& Zucca C. (2009). Identification of hyperspectral vegetation indices for Mediterranean pasture characterization. Int. J. Appl. Earth Observ. Geoinform., 11, 233-243. DOI: 10.1016/j.jag.2009.02.003.

Gao, B.-C. (1996). NDWI - A normalized difference water index for remote sensing of vegetation liquid water from space. Remote Sens. Environ. 58, 257-266. DOI: 10.1016/S0034-4257(96)00067-3.

Gitelson, A.A., Kaufman, Y. \& Merzlyak M.N. (1996). Use of a green channel in remote sensing of global vegetation from EOS- MODIS. Remote Sens. Environ., 58, 289-298. DOI: 10.1016/S0034-4257(96)00072-7.

Hope, A.S., Kimball, J.S. \& Stow D.A. (1993). The relationship between Tussock tundra spectral reflectance properties and biomass and vegetation composition. Int. J. Remote Sens., 14(10), 1861-1874. DOI: 10.1080/01431169308954008.

Hreško, J., Bugár, G., Petrovič, F., Mačutek, J., Kanásová, D. (2012). Morphodynamic effects on lacustrine deposits in the High Tatra Mts.. Ekológia (Bratislava), 31(4), 390-404. 
Huete, A., Didan, K., Muira, T., Rodriguez, E.P., Gao, X. \& Ferreira L.G. (2002). Overview of the radiometric and biophysical performance of the MODIS vegetation indices. Remote Sens. Environ., 83(1-2), 195-213. DOI: 10.1016/S0034-4257(02)00096-2.

Kanka, R., Kollár, J. \& Barančok P. (2005). Monitoring of climate change impacts on alpine vegetation in the Tatra Mts - first approach. Ekológia (Bratislava), 24(4), 411-418.

Kushida, K., Kim, Y., Tsuyuzaki, S. \& Fukuda M. (2009). Spectral vegetation indices for estimating shrub cover, green phytomass and leaf turnover in a sedge-shrub tundra. Int. J. Remote Sens., 30(6), 1651-1658. DOI: $10.1080 / 01431160802502632$.

Laidler, G.J. \& Treitz P. (2003). Biophysical remote sensing of arctic environments. Prog. Phys. Geog., 27(1), 44-68. DOI: 10.1191/0309133303pp358ra.

Leprieur, C., Kerr, Y.H., Mastorchio, S. \& Meunier J.C. (2000). Monitoring vegetation cover across semi-arid regions: comparison of remote observations from various scales. Int. J. Remote Sens., 21, 281-300. DOI: 10.1080/014311600210830.

Malenovský, Z., Mishra, K.B., Zemek, F., Rascher, U. \& Nedbal L. (2009). Scientific and technical challenges in remote sensing of plant canopy reflectance and fluorescence. J. Exp. Bot., 60(11), 2987-3004. DOI: 10.1093/ jxb/erp156.

Milton, E.J., Schaepman, M.E., Anderson, K., Kneubühler, M. \& Fox N. (2009). Progress in field spectroscopy. Remote Sens. Environ., 113, S92-S109. DOI: 10.1016/j.rse.2007.08.001.

Mutanga, O. \& Skidmore A.K. (2004). Narrow band vegetation indices overcome the saturation problem in biomass estimation. Int. J. Remote Sens., 25(19), 3999-4014. DOI: 10.1080/01431160310001654923.

Ollinger, S.V. (2011). Sources of variability in canopy reflectance and the convergent properties of plants. New Phytol., 189, 375 - 394. DOI: 10.1111/j.1469-8137.2010.03536.x.

Psomas, A., Kneubuehler, M., Huber, S., Itten, K. \& Zimmermann N.E. (2011). Hyperspectral remote sensing for estimating aboveground biomass and for exploring species richness patterns of grassland habitats. Int. J. Remote Sens., 32(24), 9007-9031. DOI: 10.1080/01431161.2010.532172.

Riedel, S.M., Epstein, H.E. \& Walker, D.A. (2005). Biotic controls over spectral reflectance of arctic tundra vegetation. Int. J. Remote Sens., 26(11), 2391-2405. DOI: 10.1080/01431160512331337754.

Rouse, J.W., Hass, R.H., Shell, J.A. \& Deering D.W. (1974). Monitoring vegetation systems in the Great Plains with ERTS-1. In Proceedings of the $3^{\text {rd }}$ Earth Resources Technology Satellite Symposium 1 (pp. 309-317). Washington: NASA.

Rundquist, B.C. (2002). The influence of canopy green vegetation fraction on spectral measurements over native tallgrass prairie. Remote Sens. Environ., 81, 129-135. DOI: 10.1016/S0034-4257(01)00339-X.

Running, S.W., Baldocchi, D.D., Turner, D.P., Gower, S.T., Bakwin, P.S. \& Hibbard K.A. (1999). A global terrestrial monitoring network integrating tower fluxes, flask sampling, ecosystem modeling and EOS satellite data. Remote Sens. Environ., 70(1), 108-127. DOI: 10.1016/S0034-4257(99)00061-9.

Scurlock, J.M.O., Johnson, K. \& Olson R.J. (2002). Estimating net primary productivity from grassland biomass dynamics measurements. Glob. Change Biol., 8(8), 736-753. DOI: 10.1046/j.1365-2486.2002.00512.x.

Shen, M., Tang, Y., Klein, J., Zhang, P., Gu, S., Shimono, A. \& Chen J. (2008). Estimation of aboveground biomass using in situ hyperspectral measurements in five major grassland ecosystems on the Tibetan Plateau. J. Plant Ecol., 1(4), 247-257. DOI: 10.1093/jpe/rtn025.

StatSoft, Inc. (2009). STATISTICA (data analysis software system), version 9.0. www.statsoft.com.

Van Leeuwen, W. J. D. \& Huete A.R. (1996). Effects of standing litter on the biophysical interpretation of plant canopies with spectral indices. Remote Sens. Environ., 55(2), 123-138. DOI: 10.1016/0034-4257(95)00198-0.

Vescovo, L. \& Gianelle D. (2008). Using the MIR bands in vegetation indices for the estimation of grassland biophysical parameters from satellite remote sensing in the Alps region of Trentino (Italy). Adv. Space Res., 41(11), 1764-1772. DOI: 10.1016/j.asr.2007.07.043.

Vogelmann, J.E., Rock B.N. \& Moss D.M. (1993). Red edge spectral measurements from sugar maple leaves. Int. J. Remote Sens., 14, 1563-1575. DOI: 10.1080/01431169308953986. 